\title{
Thirty-Five Years of Peer-Reviewed Publishing by North American Economics PhDs: Quantity, Quality, and Beyond
}

https://doi.org/10.1515/openec-2020-0005

Received Aug 3, 2019; accepted Jan 21, 2020

\begin{abstract}
We provide a descriptive analysis of various qualities of peer-reviewed journal publications of graduates of North American economics PhD programs between 1980 and 2014. We find that the share of singleauthor papers in all published papers diminishes from 60\% in 1980 to 50\% in 1990 and then further down to $20 \%$ in 2014. All-female and mixed-gender author teams publish significantly less compared with all-male author teams between 1980 and 1999, but we find no significant difference after 2000. While male authors are over-represented in micro and macroeconomics, female authors are over-represented in labor and development economics. Although the quality of outlets for most fields does not change much over years, labor economics and economic history are published significantly better after 2000.
\end{abstract}

Keywords: Economics PhD; Research Activity; Co-authorship; Subfields of Economics; Gender

JEL: A11, A14

\section{Introduction}

North American universities produce a significant number of economics $\mathrm{PhD}$ graduates; the average size of a graduating cohort each year has been slightly more than one thousand students since the late 1980s. Although such cohort sizes may be comparable to those in other competing markets, North American PhD students have a higher quality publication record on average compared with their peers in other countries or regions. ${ }^{1}$ A disproportionately large share of the world's eminent economists are graduates of North American economics departments, as documented by Frey and Pommerehne (1988).

The aim of this paper is to deliver detailed descriptive evidence on publication patterns of graduates of North American economics departments' PhD programs, which we refer to as North American PhDs throughout this paper. Conley et al. (2013) show that North American PhDs deliver significantly fewer publications both in quantity as well as in quality around the time they would be expected to be up for tenure. This paper aims to open the black box of what lies beneath these observed quantity and quality patterns. Specifically, we ask how co-authorship, gender composition of collaborations, and involvements in various subfields of economics varied for North American PhDs since 1980. We employ complete publication records from the EconLit between 1980 and 2014 for the population of North American PhDs who graduated between 1970

\footnotetext{
*Corresponding Author: Ali Sina Önder: Dept. of Economics and Finance, University of Portsmouth, PO1 3DE, Portsmouth, UK; E-mail: ali.onder@port.ac.uk

Hakan Yilmazkuday: Dept. of Economics, Florida International University, Miami, FL 33199, USA; e-mail: hyilmazk@fiu.edu 1 Frey and Eichenberger (1993) provides a detailed discussion comparing US and European academic economists. Önder and Schweitzer (2017) investigates the publication data of economics PhDs of top universities in German-speaking countries and show that these are more similar to North American non-top thirty departments than to top thirty departments in terms of publication quality. Cardoso et al. (2010) shows that North American labor economists produce higher quality publications compared to their European colleagues.
} 
and 2009. Using all journals listed in the EconLit database, as opposed to restricting our analysis to a limited number of top journals, such as the top three or top five journals, as done in the existing literature, we are able to deliver more comprehensive insights.

A summary of our findings and contributions is as follows:

(1) The share of North American PhDs publishing single-author papers in the total publications diminishes over time. Using publication data from the top journals, Hamermesh (2013) and Card and DellaVigna (2013) make a similar observation and document that the number of authors per paper increases from the 1960s and the 1970s, respectively. ${ }^{2}$ It is important to emphasize that, unlike previous studies that focus on a limited number of journals, our observation is based on the complete EconLit database. We find that coauthored papers are published in higher quality journals compared to single-author papers. While two-author papers are published on average in higher quality journals during 1980-1999, after 2000, three-author papers are published in higher quality journals than two-author papers are published in. This finding is in line with the findings of Kuld and O'Hagan (2018), who document that a striking increase in quarto-plus economics papers and also show that economists publish single-author publications in the early stages of their careers but team up soon after. Using an impressively large number of publications from the RePEc, Rath and Wohlrabe (2016a) show that the team size of economists has steadily been increasing throughout the 1990s and 2000s and show that a larger team size is correlated with better quality publications. Our findings confirm this for a wider time horizon using North American PhDs' publications in the EconLit.

(2) We observe little variation in different fields' shares in total publications over the course of three decades. Card and DellaVigna (2013) also find little variation in fields using data from the top five journals. Microeconomics, econometrics, and experimental economics research are published in the top journals, while macroeconomics, public economics, industrial organization, finance, health and urban economics, and development economics are published in lower quality journals. Labor and economic history are published in higher quality journals after 2000.

(3) Female authors and author teams that include at least one female have an increasing share in total publications over time. Hamermesh (2013) documents a similar trend for the share of female authors for publications in the American Economic Review (AER), Journal of Political Economy (JPE), and Quarterly Journal of Economics (QJE). We further investigate the publication quality and quantity of all-male, all-female, and mixed author teams, and compare their output before and after 2000. All-female and mixed author teams publish significantly less in terms of quantity and quality compared with all-male author teams during 19801999. However, we find no significant difference between the publication qualities of all-male, all-female, or mixed author teams after 2000. Moreover, author teams containing at least one author who is a graduate of a top thirty department ${ }^{3}$ publish significantly more in terms of quantity and quality compared with author teams of non-top thirty graduates.

(4) We further document the distribution of their publications over different fields. Male authors are proportionally over-represented in microeconomics and macroeconomics, whereas female authors are overrepresented in labor economics and development economics. Nevertheless, the average quality of the publications are fairly similar in all fields.

The remainder of the paper is organized as follows. We document our data sources in the next section, present our results and discuss our findings in the third section. The last section concludes.

2 Observations of Card and DellaVigna (2013) are restricted to AER, Econometrica, JPE, QJE, and REStud. Hamermesh (2013) considers AER, JPE, QJE, and other leading American general economics journals in one year in each decade from the 1960s.

3 These are the top thirty North American economics departments ranked in Coupé (2003). 


\section{Data}

We collect data on economics PhDs graduating from US and Canadian economics departments between 1970 and 2009 and their publications between 1980 and 2014. Lists of PhDs over these years are collected by the American Economic Association and published in specific issues of the Journal of Economic Literature and the American Economic Review. We obtain publication data from the EconLit. By matching names of PhDs to authors' names in the EconLit database, we obtain a complete list of PhDs' publications complete list of publications. ${ }^{4}$

Table 1 documents the number of all peer-reviewed EconLit publications and the number of publications between 1980 and 2014 that contained at least one North American PhD in the list of authors. These publications are divided into three major groups in the table: the first three columns are based on all the journals contained in the EconLit database; the second three columns are based on the top twenty journals only; and the last three columns are based on the top five journals only. In 1980-84, publications that contain at least one North American $\mathrm{PhD}$ as an author account for $22.3 \%$ of all EconLit publications, $40.6 \%$ of the top twenty economics journals, and 42.5\% of the top five journals. Between 1980 and 2014, the average percentage share of publications containing at least one North American PhD author is $22 \%, 50 \%$, and $58 \%$ for all journals, for the top twenty journals, and for the top five journals, respectively. It is important to notice that North American $\mathrm{PhD}$ authors make up a larger share in the top quality journals than in the overall publications in the EconLit database. This dominance becomes more pronounced in later years: about $17 \%$ of all peer-reviewed EconLit publications between 2010 and 2014 contain at least one North American PhD among their authors, while almost $67 \%$ of all top five journal publications have at least one North American $\mathrm{PhD}$ author.

This simple observation establishes an interesting stylized fact: top economics journals are heavily and disproportionately populated by North American PhDs. Hence, a detailed look into the publications of North American PhDs necessarily provides a comprehensive picture of research patterns and trends not only in a significant portion of peer-reviewed publications, but also in the majority of top journal publications. Therefore, any trends revealed in the publication patterns of North American PhDs will be reflected in the overall ruling trend in economics research in general as discussed in detail in the next section.

\section{Results}

\subsection{Team Size}

We document how team sizes have evolved between 1980 and 2014 based on our investigation of EconLit publications where at least one North American $\mathrm{PhD}$ listed as an author. We refer to such publications as North American PhDs' publications throughout this paper. Figure 1a shows how the number of North American PhDs' publications evolves over years disaggregated by the size of the author team; Figure $1 \mathrm{~b}$ shows their respective percentage shares.

The number of North American PhDs' publications steadily increases over the years, which should not be surprising given the increase in the number of journals as well as the number of published articles per journal over the last several decades. Using a selection of economics journals, Laband and Piette (1994) show that the market for publications grew rapidly between 1970 and 1990 at the extensive (number of journals) as well as the intensive margin (articles per journal). The EconLit database also reveals a dramatic increase in

\footnotetext{
4 Most author disambiguation algorithms deal with systematic mapping of author names. Our disambiguation procedure is based on a graph theoretic approach and follows a hierarchical process, as explained in detail in the appendix secion of Önder et al. (2019). Since the current analysis employs a subset of the data that are used in Önder et al. (2019), we encourage interested readers to refer to this other source for more information. Gender identification is from an earlier version of this dataset which is published in Conley et al. (2016) and employs a simple directory-based name recognition. These codes are available on request.
} 


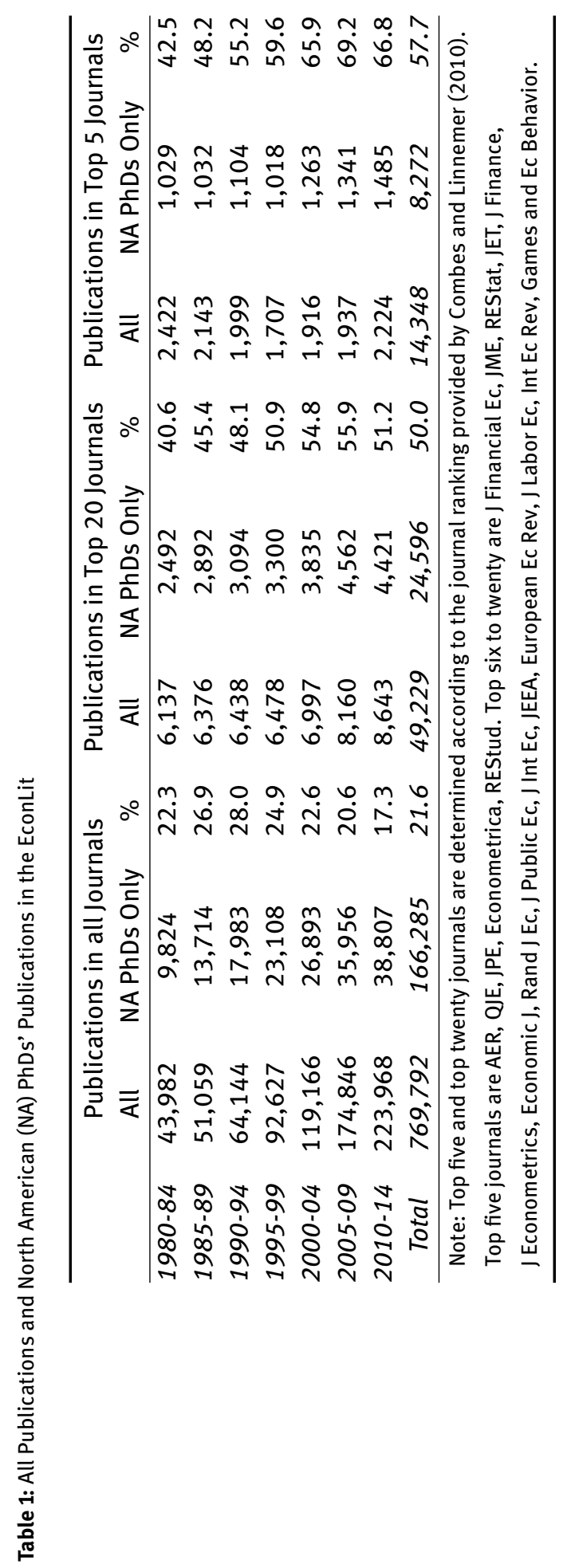




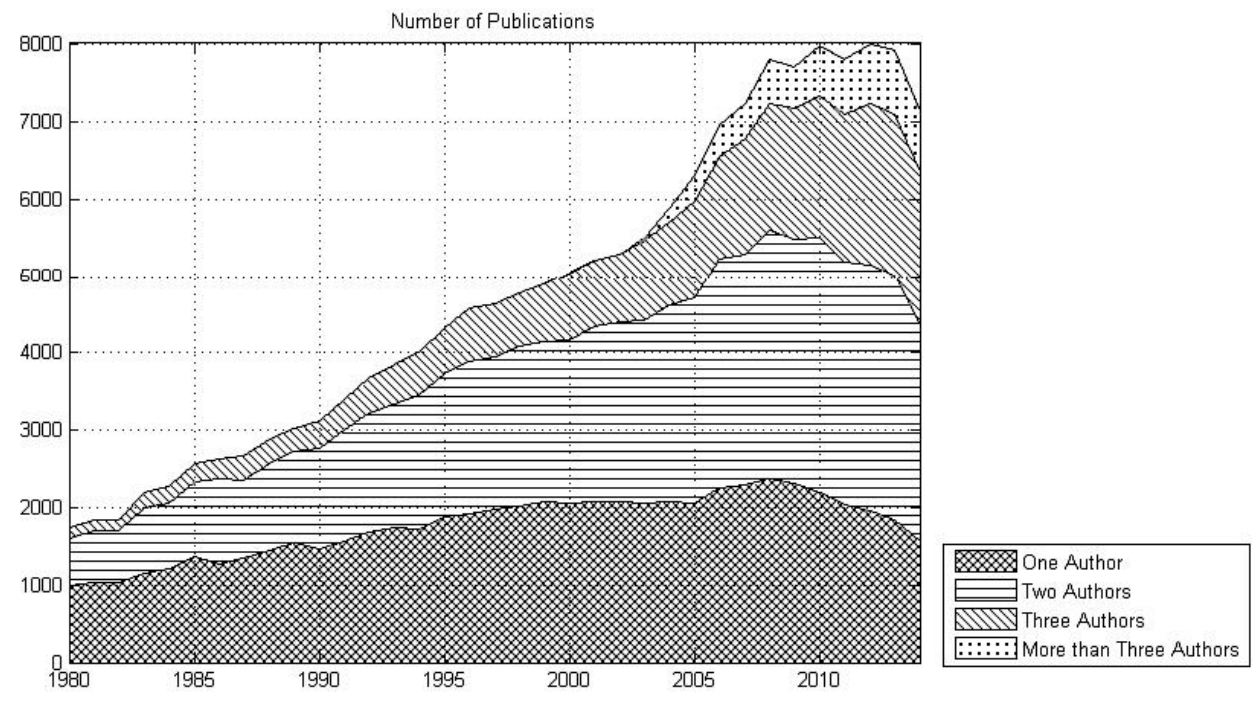

(a)

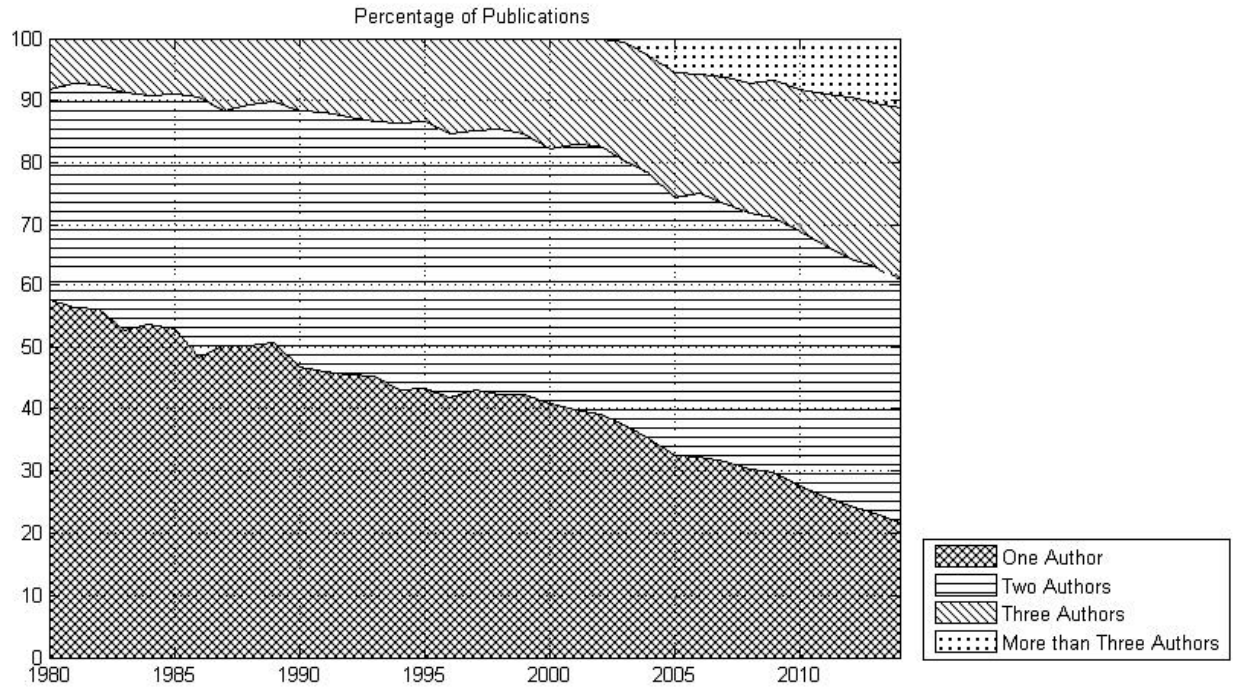

(b)

Figure 1: North American PhDs' Number of Publications (a); and Share of North American PhDs' Publications based on the Size of the Author-Teams (b)

the extensive margin: between 1980 and 1984, there are 326 distinct journals in the EconLit database, which increases to 523 in 1990-94, 975 in 2000-04, and 1,389 in 2010-14. Comparing the number of distinct journals with the number of articles (shown in the first column of Table 1), we find that the average number of articles per journal has not experienced a steady and strong increase at all over the last 35 years; there are 135 articles per journal in 1980-84, 122 in 1990-94 and 2000-04, and 161 in 2010-14.

The share of single-author papers diminishes from about 60\% in 1980 to about 20\% in 2014. Papers with two authors account for $30 \%$ of all publications in 1980, which increases to $40 \%$ in the late 1980 s, and has remained around $40 \%$ since then. Three-author papers make up less than $10 \%$ of all publications in 1980 ; their share increases to 20\% in 2005 and 30\% in 2014. The lists of authors of publications that have more than three authors appear in EconLit starting in 2000. Prior to 2000, publications that have more than three 


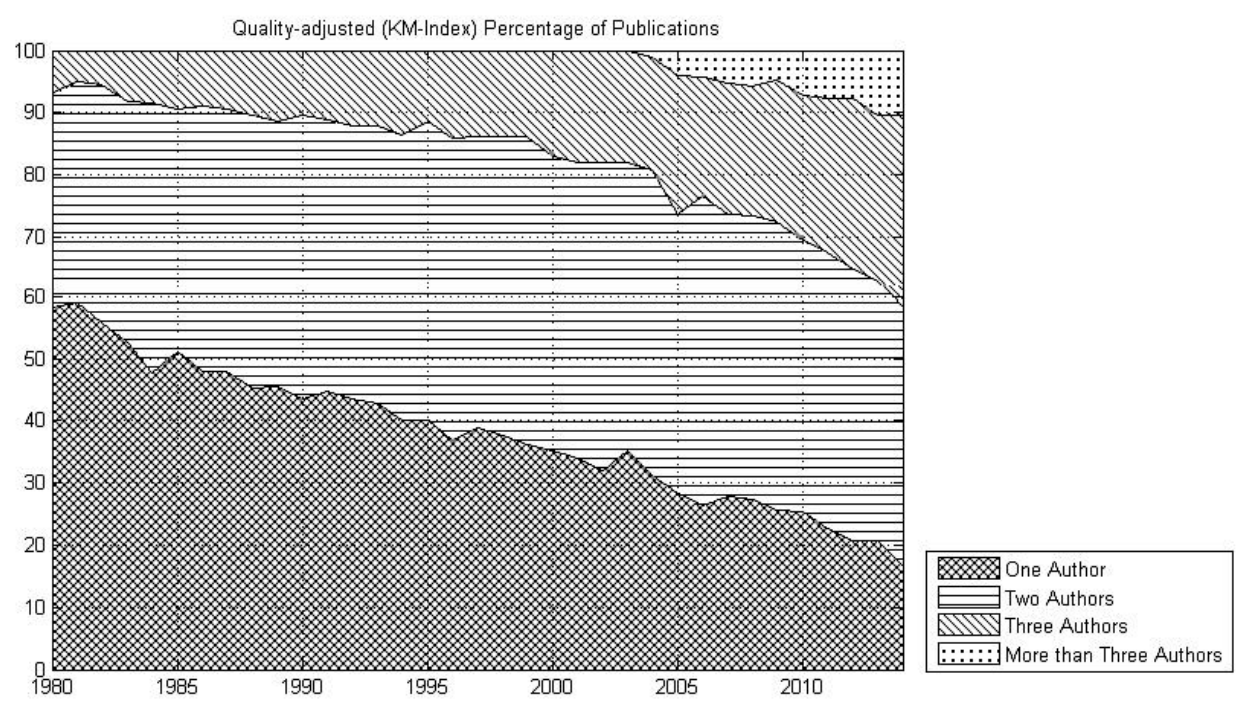

Figure 2: Share of Quality-adjusted (using KM-index) Publications based on the Size of the Author-Team

authors are listed as single-author papers under the name of the first author. Between 1985 and 2000, we identify 1,125 such cases in 229,584 publications. Thus, even if these are wrongly identified as single-author publications in the EconLit database, there are not many of such cases. Publications with more than three authors account for less than $5 \%$ of all publications in 2005. The share of publications with more than three authors increases in recent years and reaches slightly above 10\% in 2014. Hamermesh (2013) documents a similar trend toward increased coauthorship in top economics journals between 1960 and 2010. We confirm that this trend is not restricted to top journals, and it applies to the whole economics-publishing scene over the last decades.

In Figure 2, the publications are weighted using the Kalaitzidakis et al. (2003) journal quality weights, which is referred to as the KM-index. Each publication in a given journal is multiplied by a coefficient that shows how many top journal publications are equivalent to the current publication. ${ }^{5}$ The share of two-author publications in all quality-adjusted publications increases from 30\% to almost 50\% in 1995 and 2000, and it remains above $40 \%$ as of 2014. It is an interesting finding that two-author North American PhDs' publications have the largest share in quality-adjusted publications from the early 1990s onwards. This means that twoauthor papers are published more frequently in better quality journals compared to papers by larger teams or single authors. ${ }^{6}$

\subsection{Fields of Economics Research}

We investigate the shares of different fields in the overall research activity of North American PhDs in this section. We observe the reported JEL codes (consisting of a letter and two digits) in each publication and assign each one to a field within economics. We follow Card and DellaVigna (2013) in how we group the JEL codes for major fields, except that we do not distinguish between theory and microeconomics. Figure 3a shows the absolute number of each field found in North American PhDs' publications. It is important to note

5 We cut off the KM-index at 0.012 and use this index value for all journals that are not covered by the KM-index.

6 Using an alternative journal quality index such as that of Combes and Linnemer (2010), referred to as the CL-index, we obtain qualitatively very similar results. For journals that are not covered by the CL-index, we use the lowest quality weight assigned in the CL-index. 
Table 2: Fields Mentioned in JEL Classifications of North American PhDs' Publications

\begin{tabular}{cccccccc}
\hline & $1980-84$ & $1985-89$ & $1990-94$ & $1995-99$ & $2000-04$ & $2005-09$ & $2010-14$ \\
\hline Microeconomics & 1,903 & 2,487 & 2,854 & 4,046 & 5,307 & 7,477 & 10,310 \\
Macroeconomics & 1,869 & 2,504 & 2,914 & 4,407 & 5,146 & 6,724 & 7,894 \\
Labor Econ. & 1,450 & 1,735 & 2,299 & 3,537 & 4,782 & 6,092 & 7,299 \\
Econometrics & 449 & 739 & 944 & 1,323 & 1,487 & 1,908 & 3,100 \\
Industrial Org. & 1,029 & 1,495 & 1,975 & 3,052 & 4,205 & 6,339 & 7,702 \\
International Econ. & 1,059 & 1,481 & 2,019 & 3,144 & 4,234 & 5,469 & 5,572 \\
Finance & 697 & 1,085 & 2,311 & 3,534 & 4,753 & 6,435 & 8,758 \\
Public Econ. & 1,146 & 1,466 & 1,253 & 1,843 & 2,329 & 3,163 & 4,109 \\
Health \& Urban Econ. & 517 & 729 & 1,664 & 2,702 & 3,670 & 5,102 & 6,099 \\
Development Econ. & 188 & 252 & 1,574 & 3,848 & 6,558 & 8,185 & 9,229 \\
Econ. History & 216 & 285 & 200 & 255 & 315 & 415 & 458 \\
Experimental Econ. & 1 & 69 & 40 & 40 & 49 & 149 & 277 \\
\hline
\end{tabular}

that a single publication can belong to various fields if these are indicated in its JEL codes; hence, a single publication may count as a publication in, for example, econometrics and public economics at the same time. This is the reason why the sum of the number of publications in each field, as shown in Figure 3a, is larger than the total publications shown in Figure 1a. Percentage shares of different fields are shown in Figure 3b. Table 2 documents how many times a particular field shows up in publications' JEL codes in a given five-year window.

The JEL classification system underwent a significant update in 1990 and new JEL codes were introduced. The three-digit JEL classification codes were used from 1970 until 1990. The new JEL codes provide a finer differentiation between various topics. Although Card and DellaVigna (2013) provide a careful correspondence between the old and the new JEL codes, there cannot be a one-to-one correspondence. Therefore, most of the jump which we observe in and around 1990 (as shown in Figures 3a and 3b) may be due to this update of the JEL classification system.

Macroeconomics has had a consistent share of about $15 \%$ to $20 \%$ in all research output of North American PhDs over the years. Similarly, international economics, industrial organization, and econometrics have maintained a constant overall share over the decades. Finance and development economics have increased their shares since the JEL code updating in 1990, but their shares have continued to grow since the mid1990s. The share of finance in all publications grew from slightly above 10\% in 2000 to almost $15 \%$ in 2014. Development economics grew from about 10\% in 1995 to more than $15 \%$ in 2005, then it declined back to $10 \%$. Economic history seems to have lost some significant share immediately after 1990, probably due to the revision of the JEL classification system. Although the shares of different fields in total publications do not remain constant over the years, we observe little variation in their shares over the course of three decades. This observation is line with findings of Card and DellaVigna (2013), who report little variation in fields using the data from the top five journals; and Rath and Wohlrabe (2016b), who document changes in various fields revealed in RePEc papers between 2007 and 2013.

We weigh the number of JEL codes that appear in publications by the quality index of these publications using the KM-index. Figure 4 shows the percentage share of each field in quality-adjusted number of publications and thus reveals quality differences in publications across fields. Although about $10 \%$ of all publications between 1995 and 2014 carry microeconomics JEL codes, the share of microeconomics in the quality-adjusted number of publications is about $20 \%$ in the same period. This indicates that microeconomics publications received, on average, higher quality weights than most publications in other fields. Finance and international economics are among the fields that have a smaller quality-adjusted share than their nominal share. One of the most remarkable increases in shares is seen in the field of econometrics, which accounts consistently for $3 \%$ to $5 \%$ of total publications, although this share increases to almost $10 \%$ when quality-adjusted num- 


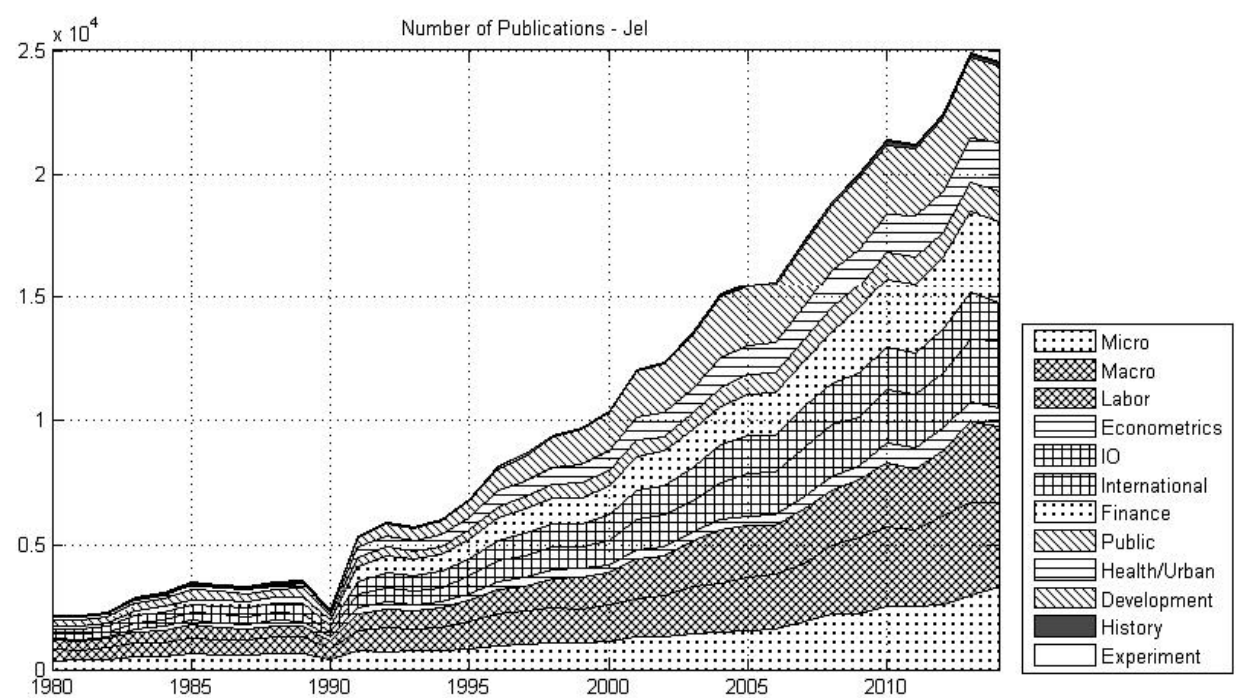

(a)

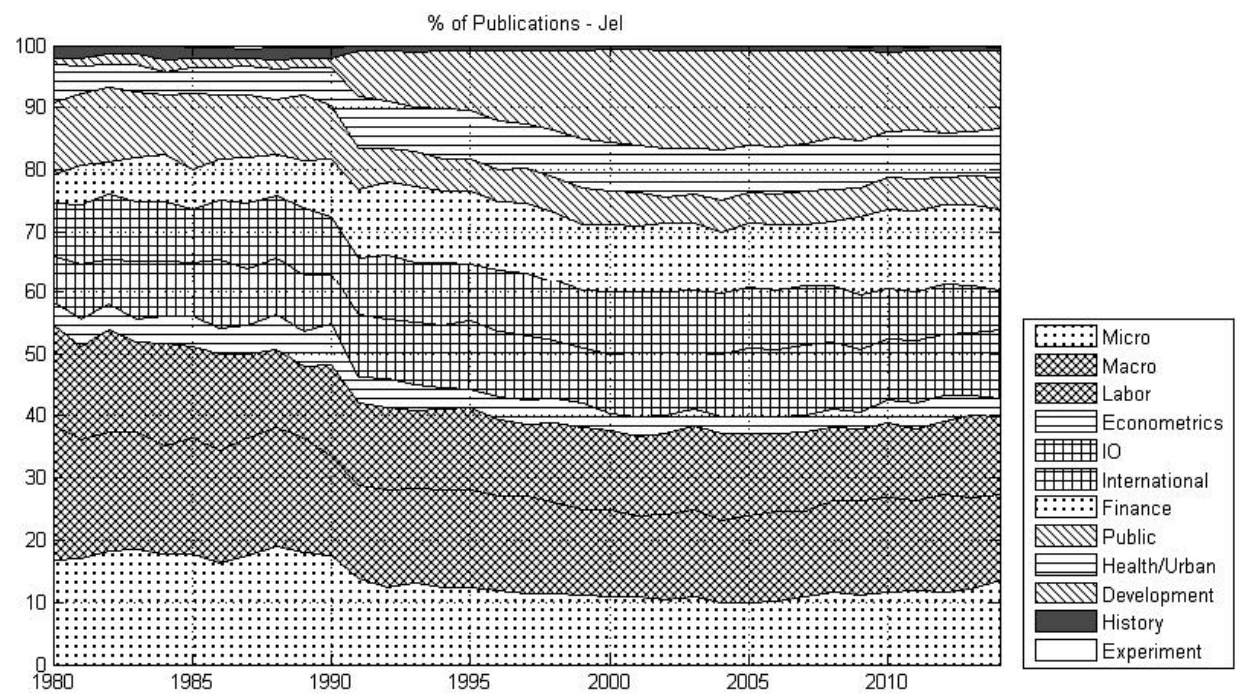

(b)

Figure 3: North American PhDs' Total Publications across Major Fields of Economics (a); and Share of Fields in North American PhDs' Total Publications (b)

ber of publications are considered. Using the quality weights of the CL-index does not yield any qualitative differences in our observations.

Table 3 shows the estimated coefficients obtained from regressing the publication quality based on the KM- and CL-indexes shown in the first two columns of the table on the interactions of time and field dummy variables. ${ }^{7}$ The two different quality measures employed in this analysis, namely the KM- and CL-indexes, differ in how strictly and how quickly they discount the quality of a journal as one moves down the rank-

7 The dependent variable in specification (1) is the KM-index that takes values between 0.012 and 1 . The mean, median, and the standard deviation of the dependent variable are $0.0996,0.012$, and 0.2 respectively. The dependent variable in specification (2) 


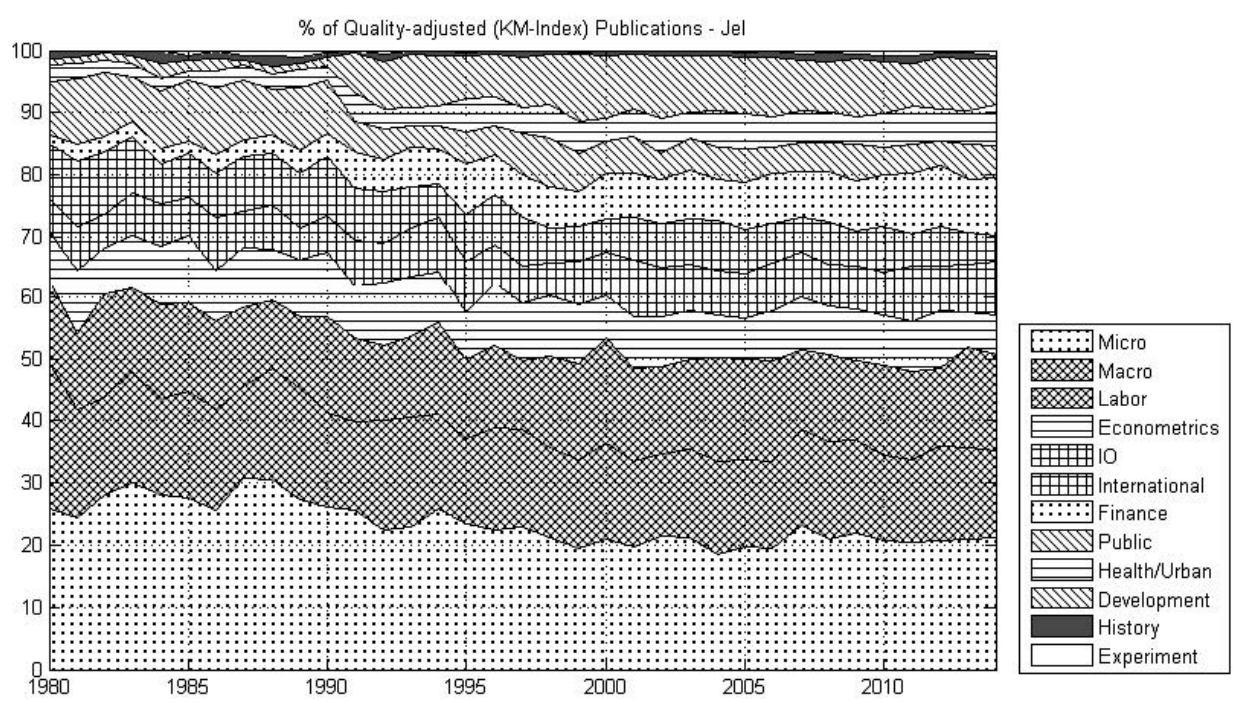

Figure 4: Share of Fields in North American PhDs' Quality-Adjusted (using KM-index) Publications

ing list. For example, the KM-index offers a rather strict discounting where the quality weights of journals decrease very quickly as one moves down the journal list. The CL-index is based on groups of journals in which the same quality index is assigned to journals in the same group; this produces a discounting that is not as steep as the one offered by the KM-index. Accordingly, the estimated coefficients in Table 3 represent how these quality-based publications differ across fields, where the size of the estimates reveals the difference with respect to the average quality across fields; for example, the positive and significant coefficient of 0.0794 for microeconomics (1980-1999) under the KM-index shows that there were 0.0794 more qualityadjusted microeconomics publications between 1980-1999 compared to average quality publications in all fields. 
Table 3: North American PhDs' Publication Quality based on Fields: $1980-99$ vs. $2000-14$

\begin{tabular}{|c|c|c|}
\hline & $\begin{array}{c}\text { (1) } \\
\text { KM-Index }\end{array}$ & $\begin{array}{c}\text { (2) } \\
\text { CL-Index }\end{array}$ \\
\hline \multirow[t]{2}{*}{ Micro (1980-1999) } & $0.0794^{\star \star \star}$ & $0.0932^{\star \star \star}$ \\
\hline & $(0.00301)$ & $(0.00329)$ \\
\hline \multirow[t]{2}{*}{ Micro (2000-2014) } & $0.0509^{\star \star \star}$ & $0.0627^{\star \star \star}$ \\
\hline & $(0.00178)$ & $(0.00203)$ \\
\hline \multirow[t]{2}{*}{ Macro (1980-1999) } & -0.00207 & $-0.0216^{\star \star \star}$ \\
\hline & $(0.00257)$ & $(0.00297)$ \\
\hline \multirow[t]{2}{*}{ Macro (2000-2014) } & $0.00309^{+}$ & $-0.00752^{\star \star \star}$ \\
\hline & $(0.00164)$ & $(0.00193)$ \\
\hline \multirow[t]{2}{*}{ Labor (1980-1999) } & 0.00294 & 0.00499 \\
\hline & $(0.00296)$ & $(0.00334)$ \\
\hline \multirow[t]{2}{*}{ Labor (2000-2014) } & $0.00638^{\star \star \star}$ & $0.0169^{\star \star \star}$ \\
\hline & $(0.00184)$ & $(0.00213)$ \\
\hline \multirow[t]{2}{*}{ Econometrics (1980-1999) } & $0.132^{\star \star \star}$ & $0.0993^{\star \star \star}$ \\
\hline & $(0.00494)$ & $(0.00482)$ \\
\hline \multirow[t]{2}{*}{ Econometrics (2000-2014) } & $0.0925^{\star \star \star}$ & $0.0567^{\star \star \star}$ \\
\hline & $(0.00331)$ & $(0.00333)$ \\
\hline \multirow[t]{2}{*}{ Ind. Org. (1980-1999) } & $-0.0349^{\star \star \star}$ & $-0.0259^{\star \star \star}$ \\
\hline & $(0.00271)$ & $(0.00319)$ \\
\hline \multirow[t]{2}{*}{ Ind. Org. (2000-2014) } & $-0.0238^{\star \star \star}$ & $-0.0266^{\star \star \star}$ \\
\hline & $(0.00157)$ & $(0.00193)$ \\
\hline \multirow[t]{2}{*}{ International (1980-1999) } & $-0.0189^{\star \star \star}$ & 0.00185 \\
\hline & $(0.00271)$ & $(0.00337)$ \\
\hline \multirow[t]{2}{*}{ International (2000-2014) } & $-0.0209^{\star \star \star}$ & $-0.0178^{\star \star \star}$ \\
\hline & $(0.00155)$ & $(0.00202)$ \\
\hline \multirow[t]{2}{*}{ Finance (1980-1999) } & $-0.0536^{\star \star \star}$ & $-0.0370^{\star \star \star}$ \\
\hline & $(0.00261)$ & $(0.00329)$ \\
\hline \multirow[t]{2}{*}{ Finance (2000-2014) } & $-0.0335^{\star \star \star}$ & $-0.0215^{\star \star \star}$ \\
\hline & $(0.00158)$ & $(0.00193)$ \\
\hline \multirow[t]{2}{*}{ Public (1980-1999) } & $-0.0121^{\star \star \star}$ & 0.000627 \\
\hline & $(0.00326)$ & $(0.00380)$ \\
\hline \multirow[t]{2}{*}{ Public (2000-2014) } & $-0.0118^{\star \star \star}$ & -0.00309 \\
\hline & $(0.00208)$ & $(0.00252)$ \\
\hline \multirow[t]{2}{*}{ Health\&Urban (1980-1999) } & $-0.0520^{\star \star \star}$ & $-0.0697^{\star \star \star}$ \\
\hline & $(0.00273)$ & $(0.00322)$ \\
\hline \multirow[t]{2}{*}{ Health\&Urban (2000-2014) } & $-0.0327^{\star \star \star}$ & $-0.0419^{\star \star \star}$ \\
\hline & $(0.00164)$ & $(0.00198)$ \\
\hline \multirow[t]{2}{*}{ Development (1980-1999) } & $-0.0194^{\star \star \star}$ & $-0.0235^{\star \star \star}$ \\
\hline & $(0.00288)$ & $(0.00344)$ \\
\hline \multirow[t]{2}{*}{ Development (2000-2014) } & $-0.0379^{\star \star \star}$ & $-0.0603^{\star \star \star}$ \\
\hline & $(0.00134)$ & $(0.00164)$ \\
\hline \multirow[t]{2}{*}{ History (1980-1999) } & $-0.0309^{\star \star \star}$ & -0.00116 \\
\hline & $(0.00657)$ & $(0.00737)$ \\
\hline History (2000-2014) & $0.0164^{\star}$ & $0.0380^{\star \star \star}$ \\
\hline & $(0.00651)$ & $(0.00709)$ \\
\hline Experimental (1980-1999) & $0.0572^{\star}$ & $0.0723^{\star \star}$ \\
\hline & $(0.0258)$ & $(0.0240)$ \\
\hline Experimental (2000-2014) & $0.0568^{\star \star \star}$ & $0.0792^{\star \star \star}$ \\
\hline & $(0.0141)$ & $(0.0130)$ \\
\hline Control for Coauthorship & Yes & Yes \\
\hline Year Fixed Effects & Yes & Yes \\
\hline$N$ & 141392 & 141392 \\
\hline$R^{2}$ & 0.072 & 0.073 \\
\hline $\mathrm{F}$ & 143.7 & 175.0 \\
\hline
\end{tabular}


We use these estimates to compare periods of 1980-1999 and 2000-2014. Since quality index weights for journals remain constant over time, estimations shown in Table 3 reveal how the outlet quality changed over time for a given field. Some fields, including microeconomics, econometrics, and experimental economics, are consistently published in high quality journals. Other fields, such as industrial organization, finance, health and urban economics, and development economics, are published in lower quality journals. There are several interesting cases in which the field coefficients change signs or significance between the two periods or between the two quality indexes. For example, journals publishing labor economics show no significant divergence from the average journal quality between 1980 and 1999, although labor economics appears in significantly higher quality journals from 2000 to 2014. The coefficients for economic history switch signs between the two periods, that is, economic history appears in outlets that are significantly below average quality from 1980 to 1999 (according to the KM-index), but after 2000, economic history apparently switches to outlets that are of a significantly higher quality when compared with the average.

Using the KM-index, we find no significant quality divergence for macroeconomics journals from 1980 to 1999, and a barely significant positive quality from 2000 to 2014 . However, when the CL-index is used, we find that macroeconomics outlets are significantly below average quality in both periods. The reverse is true for public economics outlets; the KM-index obtains significant and negative coefficients for both periods, while the CL-index obtains no significance in either period. The publication outlets for some fields may change over the decades, while some fields move from low quality to higher quality journals or from high to lower quality journals. As Hamermesh (2013) discusses, such movements are especially relevant for general interest journals and reflect changes in fashionable topics or methodology that favor a particular field at a given time.

\subsection{Gender Teams and Quality}

In this section, we provide a detailed comparison between author teams that contain at least one female author with author teams that consist solely of male authors. For this paper, we refer to the former as femaleor-mixed author teams and to the latter as all-male author teams. In case of female-or-mixed author teams, at least one of the female authors has to be a North American $\mathrm{PhD}$, and in case of all-male author teams, at least one author has to be a North American PhD. ${ }^{8}$ We observe a steady increase in the share of publications by female-or-mixed author teams; in 1980, about 10\% of all North American PhDs' publications contain at least one female author, which increases in 2000 to slightly above $20 \%$ and to about $35 \%$ in 2014 . When quality-adjusted number of publications are considered, the share of female-or-mixed author teams in quality-adjusted publications trails slightly behind their share in total publications but this gap remains fairly small. Moreover, we find no notable difference in team sizes between all-male and female-or-mixed author teams.

Conley et al. (2016) shows that female PhDs make up about 20\% to $25 \%$ of each graduating $\mathrm{PhD}$ cohort in the 1980s and 1990s; the share of publishing female PhDs, which is defined as having at least one peerreviewed publication within six years after graduation, in any cohort is also about $20 \%$ over the same period. Hence, female PhDs were under-represented in author teams in the 1980s, but this has improved over time. One way to understand this development is that all-female author teams were more common in the 1980s, whereas this pattern is not as common in the late 1990s and 2000s since we observe more mixed author teams.

Next, we investigate the fields in which the all-male and female-or-mixed author teams publish and whether large differences can be detected in this respect. We document the average shares of fields in all-male and female-or-mixed author teams' total number of publications from 1991 to 2014 in Figure 5a. We restrict this analysis to post-1990 so that our observations are not affected by the change in the JEL classification system that took place in 1990. Comparing fields of all-male and female-or-mixed author teams, we make several interesting observations. We begin by comparing the share of different fields in the total number of publica-

8 Note that a female-or-mixed author team that consists of a single author is simply a North American female PhD. Similarly, an all-male author team that consists of a single author is a North American male PhD. 
tions. Figure 5a shows that macroeconomics accounts for about 15\% of the publications by all-male author teams and about $11 \%$ of female-or-mixed author teams. Labor economics has a larger share (more than 16\%) in publications of female-or-mixed author teams than in publications of all-male author teams (about 12\%). We also observe more than one percentage point difference between their shares in publications of all-male and female-or-mixed author teams in the fields of microeconomics and development economics. All-male author teams have a larger publication share in microeconomics and a smaller publication share in development economics. The share in all other fields for publications by all-male and female-or-mixed author teams are similar.

In order to investigate the average quality differences between all-male and female-or-mixed author teams, we calculate a per-publication quality measure for both groups in each field. We divide the qualityadjusted number of publications by the total number of publications in each field separately for the all-male and female-or-mixed author teams. This yields a measure of the average quality of publications for either group of author teams in each field. This measure has values between zero and one in which a value closer to one signals a higher average of publications. We summarize our results regarding the average publication quality measure in Figure $5 \mathrm{~b}$. In all fields, all-male teams score higher than female-or-mixed author teams in terms of the average quality of publications.

Table 4 reports the OLS coefficients when the publication quality is regressed on author teams' characteristics from 1980 to 1999 and from 2000 to $2014.9^{\circ}$ We find that research containing at least one author who is a graduate from a top thirty department among all North American economics departments is published consistently in high quality journals; this finding remains consistent over the two periods. Interestingly, research in which there is at least one female author is published in slightly lower quality journals from 1980 to 1999. However, this is not the case after 2000. In Table 4 in specification (5), we find that female participation in a publication is positively and significantly correlated with research outlet quality, but the significance is lost when we control for the size of the author teams in specifications (7) and (8). We take the quality of single-author papers as base and estimate how the publication qualities of two- and three-author papers diverge from it. There are significantly more papers with two authors than single-author papers in both periods; moreover, the quality gap is greater after 2000 compared to before 2000. Most specifications reveal that papers with three authors are published in significantly higher quality journals compared with single-author papers in both periods. Comparing the coefficients of two-author and three-author papers over the two periods, we find that two-author papers are of better quality compared with three-author papers during 1980-1999; however, three-author papers are published in higher quality journals in 2000-2014. This observation remains robust across specifications in columns (6) to (8) in Table $4 .{ }^{10}$

\section{Conclusion}

Economics PhDs from North American universities produce an important share of peer-reviewed journal publications; their share of publications in top economics journals is even larger than their share in all economics journals. A brief look into 35 years of peer-reviewed publication outcome of North American PhDs, from 1980 to 2014, reveals several interesting patterns of how publication quantity and quality are linked to various dimensions of author teams.

The share of single-author papers has diminished over time, and North American PhDs engage more in coauthored publications. The share of two-author publications increases in all quality-adjusted publications from 30\% in 1980 to almost 50\% in 1995. This share decreases to slightly above 40\% in 2014, losing ground

9 As explained in section 2, publications with more than three authors have been registered in the EconLit database since the early 2000s. Hence, we disregard publications with more than three authors in the later years of our dataset in order to maintain comparability across the two periods for this analysis.

10 When we use the CL-index instead of the KM-index as a dependent variable and run the same regressions as in Table 4, we obtain qualitatively very similar results. These results are available upon request. 


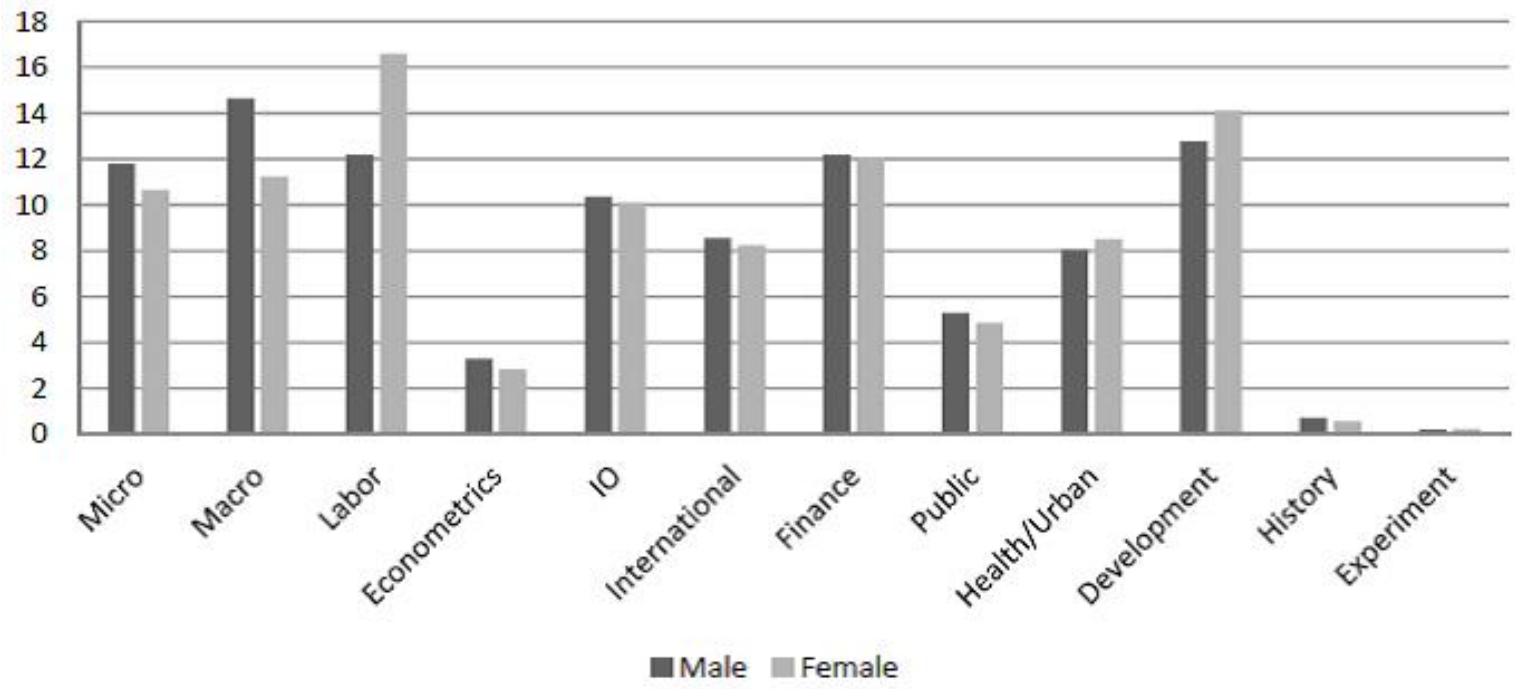

(a) based on Total Publications

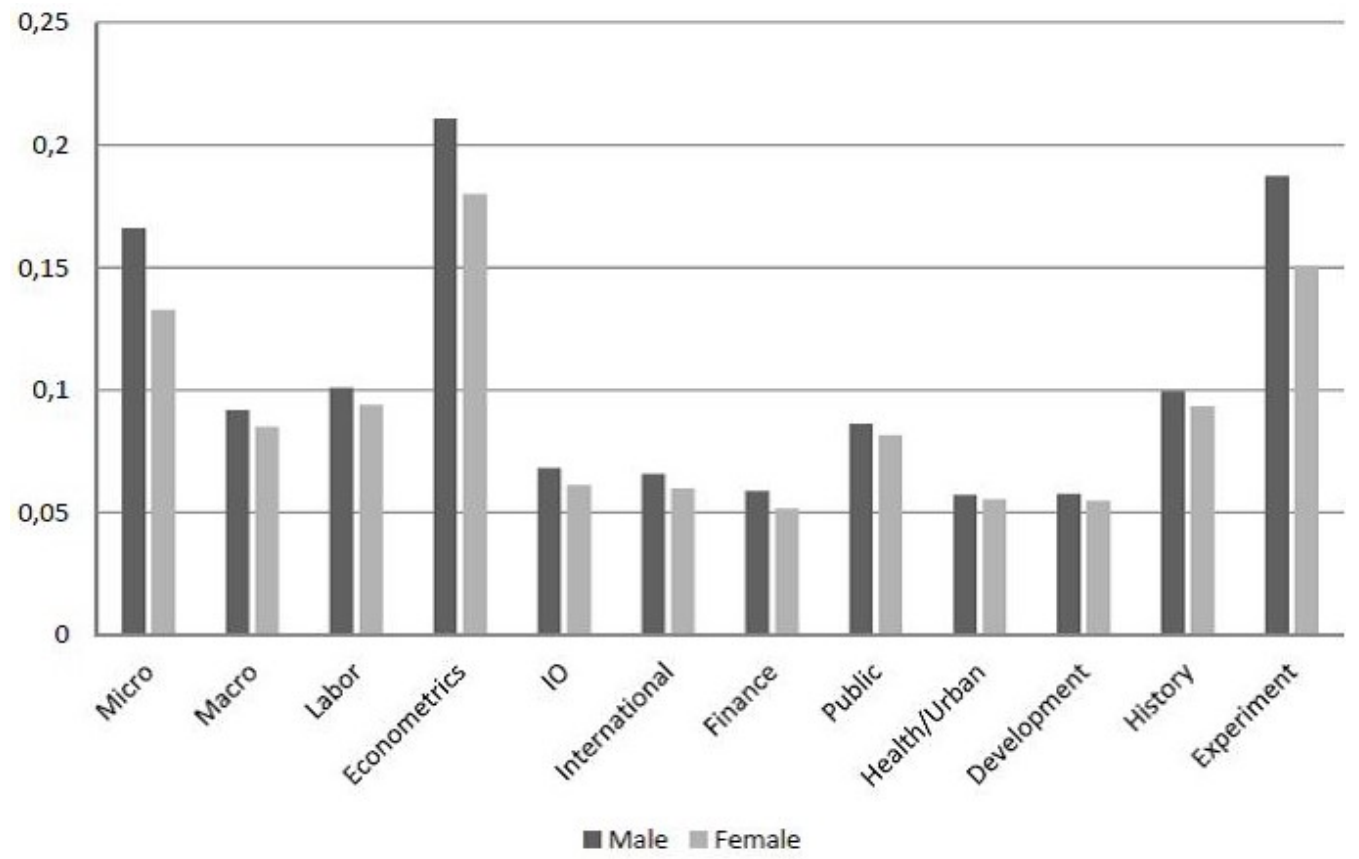

(b) based on Quality-to-Raw Ratio of Publications

Figure 5: Share of Fields in All-Male and Female-or-Mixed Author-Teams Publications, 1991-2014 


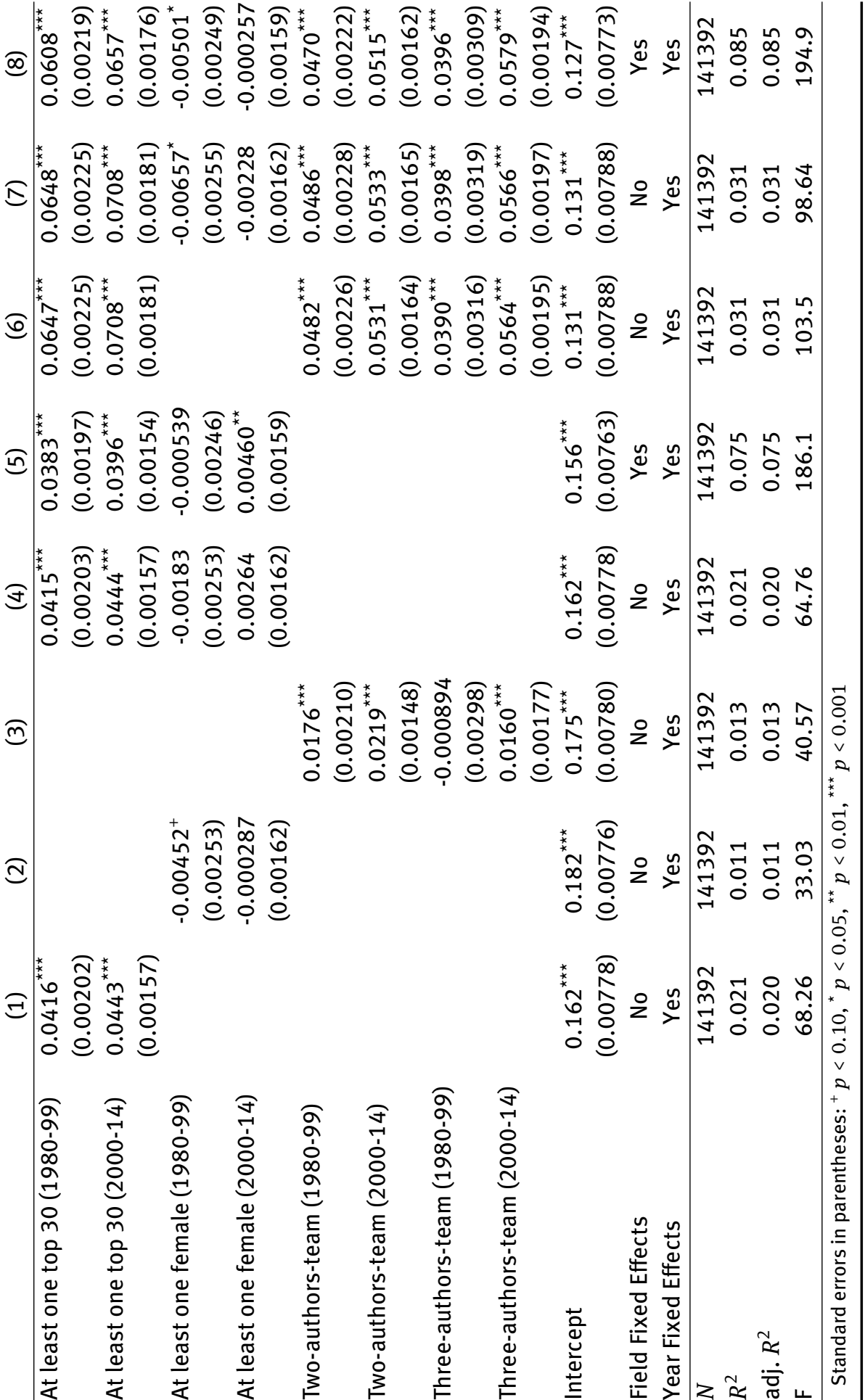


to three-author publications and to publications with more than three authors. We find that the publications from author teams that contain at least one graduate from a top thirty North American economics departments are significantly better in terms of quantity and quality compared with author teams that contain nontop thirty graduates. The publication quality of female PhDs has significantly improved over the decades, and we find no significant difference between the publication qualities of all-male author teams and female-ormixed author teams. Although we find disproportionately more female authors in some fields, especially in labor and development economics, we do not find significant quality differences in favor of female authors in these fields.

When considering publication trends in different fields, we find that research in microeconomics, econometrics, and experimental economics is published in high quality journals, whereas fields, such as macroeconomics, public economics, industrial organization, finance, health and urban economics, and development economics, are published in journals that have lower quality weights than average. Number of publications on labor economics and economic history has significantly increased in top ranked journals after 2000. It must be noted that some of these results do not remain robust when an alternative journal quality index is used.

Some patterns remain constant, while some change over 35 years. It is hard to say how individual fields may develop over the next years or decades. However, one can surely claim that author teams will grow further in size. Quality advantage has already started to shift from two-author teams to teams consisting of more than two authors during the 2000s. Given the trend over the last 35 years, it is likely that higher modes of collaboration will dominate the research environment of North American PhDs, as well as that of economists from all over the world over the next decades.

Acknowledgement: The authors would like to thank Ted Bergstrom and John Conley for helpful comments, and Sascha Schweitzer for valuable contributions to the dataset used in this study. The usual disclaimer applies.

Financial Support: This research received no specific grant from any funding agency, commercial or nonprofit sectors.

Conflict of Interests Statement: The authors have no conflicts of interest to disclose.

\section{References}

Card, D. and DellaVigna, S. (2013). Nine facts about top journals in economics. Journal of Economic Literature, 51(1):144-161.

Cardoso, A. R., Guimarães, P., and Zimmermann, K. F. (2010). Comparing the early research performance of PhD graduates in labor economics in Europe and the USA. Scientometrics, 84(3):621-637.

Combes, P.-P. and Linnemer, L. (2010). Inferring Missing Citations: A Quantitative Multi-Criteria Ranking of all Journals in Economics. Hal Archives halshs-00520325.

Conley, J. P., Crucini, M. J., Driskill, R. A., and Önder, A. S. (2013). The Effects of Publication Lags on Life-Cycle Research Productivity in Economics. Economic Inquiry, 51(2):1251-1276.

Conley, J. P., Önder, A. S., and Torgler, B. (2016). Are all economics graduate cohorts created equal? Gender, job openings, and research productivity. Scientometrics, 108(2):1-22.

Coupé, T. (2003). Revealed performances: Worldwide rankings of economists and economics departments, 1990-2000. Journal of the European Economic Association, 1(6):1309-1345.

Frey, B. S. and Eichenberger, R. (1993). American and European economics and economists. The Journal of Economic Perspectives, 7(4):185-193.

Frey, B. S. and Pommerehne, W. W. (1988). The American domination among eminent economists. Scientometrics, 14(1-2):97-110. Hamermesh, D. S. (2013). Six decades of top economics publishing: Who and how? Journal of Economic Literature, 51(1):162-172.

Kalaitzidakis, P., Mamuneas, T. P., and Stengos, T. (2003). Rankings of academic journals and institutions in economics. Journal of the European Economic Association, 1(6):1346-1366.

Kuld, L. and O'Hagan, J. (2018). Rise of multi-authored papers in economics: Demisr of the 'lone star' and why? Scientometrics, 114(3):1207-1225. 
Laband, D. N. and Piette, M. J. (1994). The relative impacts of economics journals: 1970-1990. Journal of Economic Literature, 32:640-666.

Önder, A. S. and Schweitzer, S. (2017). Catching Up or Falling Behind? Promising Changes and Persistent Patterns Across Cohorts of Economics PhDs in German-Speaking Countries from 1991 to 2008. Scientometrics, 110(3):1297-1331.

Önder, A. S., Schweitzer, S., and Yilmazkuday, H. (2019). Specialization, Distance, and Quality in Economists' Collaborations: How Diverse is Research Really? SSRN Working Paper 3125205.

Rath, K. and Wohlrabe, K. (2016a). Recent Trends in co-authorship in economics: Evidence from RePEc. Applied Economics Letters, 23(12):897-902.

Rath, K. and Wohlrabe, K. (2016b). Trends in economics ppublication represented by JEL categories between 2007 and 2013. Applied Economics Letters, 23(9):660-663. 